\title{
"PROYECTAR CON la nAtURALEZA". LA MATRIZ fLUVIAL COMO COMPONENTE CENTRAL DEL PLANEAMIENTO CONTEMPORÁNEO: CASO ÁREA METROPOLITANA DE ROSARIO.
}

\section{"DESIGN WITH NATURE". THE FLUVIAL MATRIX AS A CENTRAL COMPONENT OF CONTEMPORARY PLANNING: CASE OF ROSARIO'S METROPOLITAN AREA.}

\section{Cecilia Inés Galimbert ${ }^{1}$}

\section{RESUMEN}

La protección y resguardo del ambiente son ejes centrales del planeamiento contemporáneo a escala global. Especialmente la matriz fluvial resulta plataforma esencial de reconocimiento e identificación en la definición de proyectos e intervenciones urbano-territoriales. El presente artículo, tomando como caso de estudio al Área Metropolitana de Rosario (Argentina), se propone reflexionar críticamente sobre las transformaciones locales del planeamiento en torno al ambiente, con relación a los desarrollos a nivel internacional que se han realizado en las últimas décadas, a fin de lograr ciudades y territorios más sostenibles y de una mayor calidad de hábitat. La investigación es de carácter predominantemente cualitativa, con diversas técnicas como revisión de literatura y tratados internacionales, análisis de instrumentos de planeamiento y ordenamiento regional y local, recorridos exploratorios en el territorio, análisis de fotografías satelitales y aéreas y relevamiento de prensa periódica. Se reconoce que, a pesar de los numerosos avances de reconocimiento y protección ambiental, tanto a nivel local, como regional del ámbito territorial estudiado, aún se registran numerosos procesos con profundos impactos y efectos socio-territoriales que requieren nuevas estrategias de abordajes, acuerdos, instrumentos de intervención y gestión a fin de asegurar el derecho a la ciudad y al territorio para las generaciones futuras. Palabras clave: frentes fluviales - ambiente - áreas metropolitanas - planeamiento - desarrollo sostenible

\section{ABSTRACT}

The protection and safeguarding of the environment are central axes of contemporary planning on a global scale. The fluvial matrix is an essential platform for recognition and identification in the definition

\footnotetext{
${ }^{1}$ Doctora en Arquitectura por la Universidad Nacional de Rosario de Argentina (2015), con estudios postdoctorales en urbanismo, planeamiento y ordenamiento urbano-territorial. Es Investigadora Adjunta del Consejo Nacional de Investigaciones Científicas y Técnicas (CONICET) y del Centro Universitario de Investigaciones Urbanas y Regionales de Rosario (CURDIUR) en Argentina. Integrante del Grupo ARUCO del Departamento de Arquitectura de la Universidad de la Costa, (Barranquilla, Colombia). ORCID: https://orcid.org/0000-0001-9030-0143. E-mail: cecilia.galimberti@gmail.com
} 
of urban-territorial projects and interventions. This article, taking the Metropolitan Area of Rosario (Argentina) as a case study, aims to critically reflect on the local transformations of environmental planning, in relation to international developments that have taken place in recent decades, in order to achieve more sustainable cities and territories and a higher quality of habitat. The research is predominantly qualitative, using various techniques such as literature review and international conventions, analysis of regional and local planning and zoning instruments, exploratory studies on the territory, analysis of satellite and aerial photographs, and periodical press reviews. It is recognized that, despite the numerous advances in environmental recognition and protection, both at local and regional level in the territorial area studied, there are still numerous processes with deep socio-territorial impacts and effects that require new approach strategies, agreements, intervention and management instruments in order to ensure the right to the city and the territory for future generations.

Keywords: waterfronts - environment - metropolitan areas - planning - sustainable development

\section{INTRODUCCIÓN}

El título del presente artículo retoma la denominación del libro publicado por lan McHarg en 1969. Design with nature ha sido una obra clave en la conjunción de la planificación urbana y territorial con la ecología, abogando hacia una atenta relación sinérgica entre naturaleza y forma construida. Previamente a este libro, en 1966, dicho autor publica el artículo Ecological Determinism, a través del cual propone el uso de la ecología en el planeamiento y diseño a fin de impedir el camino hacia la necrópolis ${ }^{2}$ vaticinada previamente por Lewis Mumford, su mentor (STEINER, 2006). Justamente es Mumford quien realiza la introducción a la primera edición de Design with Nature, en la cual define a McHarg como un "planificador ecológico" que da cuenta del daño producido por el ser humano en el ambiente, desde sus primeras acciones, "destruyendo su habitabilidad" (MUMFORD, 2000, p. XVI). En el mencionado libro se plantean, en cambio, nuevas estrategias de intervención consciente, utilizando al máximo el potencial que la naturaleza ofrece (sin olvidar las necesarias restricciones para su preservación), reavivando así “la confianza en un mundo mejor" (MUMFORD, 2000, XVII).

Uno de los temas centrales trazados por McHarg consiste en la atención de la matriz fluvial en las ciudades y los territorios, atendiendo a sus diversos componentes y características; en pos de la definición

\footnotetext{
2 En el libro "La ciudad en la Historia" publicado originalmente en 1961, Mumford incorpora el concepto de necrópolis a fin de dar cuenta el destino final de la "más preciosa invención colectiva de la civilización, la ciudad" (MUMFORD, 2014, p.41); dado que, si continuara el consumo excesivo que resultan las "exaltaciones del poder desmoralizado, reducciones de la vida" (IDID, p. 175) se tendería a la destrucción y a la muerte.
} 
de proyectos atentos a sus lógicas intrínsecas (MCHARG, 2000; NDUBISI, 2002; YANG \& LI, 2016). Dicha atención por la naturaleza y los cursos de agua, no solo se reconocen desde los estudios académicos y científicos, sino también, especialmente desde las últimas décadas del siglo XX, se registra el reclamo por parte de la sociedad de recuperar los cuerpos de agua, tanto desde su saneamiento y restauración ecológica, como de un mayor acceso e interacción cotidiana, particularmente en torno a la generación de nuevos espacios públicos (BREEN \& RIGBY, 1994; GORDON, 1996; MEYER, 1999). Es así, que gran cantidad de ciudades en todo el mundo, en particular aquellas cuyas costas se encontraban ocupadas de infraestructuras portuarias e industriales, abordan diversos procesos de refuncionalización y reconversión de sus frentes agua (GALIMBERTI, 2020 y 2021).

Si bien estos intereses e iniciativas se registran desde hace más de medio siglo, especialmente con el nuevo milenio se identifica un incremento de reclamos y acciones hacia el resguardo del ambiente. En este sentido, gran parte de las ciudades a escala global han desarrollado estrategias y propuestas para lograr una mayor sostenibilidad urbano-territorial, a través de nuevas políticas ecológicas en sus frentes de agua (BUNCE \& DESFOR, 2007). La reconversión de waterfronts se posiciona como áreas de oportunidad para alcanzar una mayor integración entre la compleja matriz ambiental, de interacción continua entre ser humano y naturaleza, posibilitando conducir el camino hacia un mundo mejor y más sostenible.

El presente artículo se propone indagar en el rol de la matriz fluvial en el planeamiento contemporáneo, a fin de lograr ambientes más sostenibles; focalizando en el estudio del Área Metropolitana de Rosario (AMR), Argentina. Este caso resulta representativo, dado que, si bien desde sus orígenes se reconoce su importancia (denominada originalmente como Pago de los arroyos); es recién desde las últimas décadas del siglo XX que se inician diversas intervenciones y propuestas continuas en el tiempo que posibilitan una nueva relación entre la sociedad y su ambiente. No obstante, a pesar de dichas acciones, en los últimos años, esta región también atraviesa diversos impactos y problemáticas vinculadas a su matriz fluvial, en especial, a partir de la quema indiscriminada en el delta, lo que ocasiona un mayor compromiso y reclamos por parte de la sociedad a fin de lograr el resguardo y protección de la compleja biodiversidad existente en dicho territorio.

El artículo, posteriormente a la presente introducción se estructura en cuatro apartados. El primero, desarrolla la incorporación de la mirada ambiental en el planeamiento, así como en la definición de acuerdos y tratados internacionales en búsqueda de ciudades y ambientes más sostenibles. También así, se focaliza en distintos ejemplos, planes y procesos de transformación de frentes de agua en diversas ciudades del mundo. La segunda parte introduce y desarrolla el caso del Área Metropolitana de Rosario a partir del análisis del rol de los componentes hídricos en el planeamiento urbano-territorial desde su conformación hasta fines del siglo XX. Se verifica así, como el agua resulta central en este ámbito 
territorial, tanto para el inicio y desarrollo de sus actividades productivo-portuarias, cómo para la sociedad que ha reclamado durante décadas una mayor conexión con su frente fluvial para usos recreativos. EI tercer apartado, indaga sobre los desarrollos del planeamiento urbano-territorial en el AMR en el siglo $\mathrm{XXI}$, posibilitando diversas acciones, proyectos e intervenciones que, finalmente concretan una nueva relación entre sociedad, cultura y naturaleza, en especial, en torno a sus componentes hídricos. Asimismo, se avanza en identificar las principales problemáticas y desafíos presentes en el ámbito territorial estudiado; reconociendo, a su vez, las acciones, reclamos y propuestas para lograr un hábitat integral más sostenible. Finalmente, en el cuarto y último apartado se exponen las reflexiones finales en torno a los avances del planeamiento urbano-territorial que parten desde una atenta mirada de la matriz ambiental para avanzar hacia un mundo mejor.

\section{LA REVOLUCIÓN AMBIENTAL: NUEVAS ESTRATEGIAS Y ACCIONES A ESCALA GLOBAL}

Si bien a lo largo de la historia existen estudios y conocimientos de los impactos de la acción del hombre en el ambiente, así como propuestas para modificar estas tendencias; especialmente en la década de 1960 se plantean nuevas miradas desde distintos ámbitos que reclaman la urgente atención ambiental (ROME, 2003). En 1962 el texto denominado Silent Spring de Rachel Carson, denuncia los impactos de los pesticidas, logrando una notable repercusión en la sociedad y divulgando ampliamente la conciencia ambiental (LYTLE, 2007). En dicho contexto, lan McHarg en 1967 recibió el encargo por parte de Russell Train (Conservation Foundation) de escribir un libro que "relacionara la ecología con la planificación", frente a "la ausencia de cualquier noción medioambiental en la planificación, que en aquellos momentos era un proceso exclusivamente socio-económico" (MCHARG, 2000, p.XIII), de manera que brindó nuevas propuestas y una metodología que articulen los aspectos ambientales al planeamiento. Justamente la elección de McHarg se vincula a sus notables antecedentes en la temática, dado que además de su propia experiencia profesional (en su estudio Wallace-McHarg, Roberts y Todd), había dictado distintos cursos como, por ejemplo, El Hombre y el medio ambiente y La ecología de la ciudad; así como proyectos llevados a cabo como profesor de la Universidad de Pensilvania de Arquitectura del Paisaje y la divulgación realizada como conductor del programa de televisión de la cadena CBS denominado The House We Live In, entre 1960 y 1962, acerca de los impactos ambientales ocasionados por el ser humano. Design With nature, sus artículos científicos y conferencias, sus enseñanzas en el ámbito universitario y otras acciones, como la creación del Día de la Tierra el 22 de abril de 1970, han influido en gran medida a diversas generaciones de planificadores (YARO, 1998).

Por otra parte, a nivel mundial también se desarrollan nuevos acuerdos y tratados en torno a la atención y preservación del ambiente. En 1960 la Unión Internacional para la Conservación de la 
Naturaleza y los Recursos Naturales (IUCN) estableció el proyecto MAR para la conservación y el manejo de humedales $y$, dos años luego, se organizó una conferencia, en la cual por primera vez expertos de distintos países debatieron sobre criterios para la definición de áreas y reservas de humedales, aspectos de protección, mejora y restauración; así como el rol del ser humano en los hábitats vinculados al agua y los esfuerzos internacionales necesarios para la conservación de la biodiversidad de dichos ambientes (MATTHEWS, 2013). En los años siguientes continuaron diversas definiciones y acuerdos, hasta que, en 1971 se realizó la Conferencia de Ramsar (Irán), en la cual representantes de 18 países adhirieron a la Convención de Humedales de importancia internacional.

También a fines de los '60, las Naciones Unidas desde sus órganos subsidiarios (en especial, del Consejo Económico y Social), recomendaron la realización de una conferencia mundial general sobre el ambiente; la cual tomó lugar entre el 5 y el 16 de junio de 1972 en Estocolmo (Suecia), conocida como Primera Cumbre para la Tierra. En dicha conferencia se enunciaron diversos problemas y desafíos ambientales, proponiendo diversas líneas de actuación futura ${ }^{3}$ (MCNAMARA, 1972). posteriormente, se llevaron a cabo procesos de negociaciones sobre la necesidad de una convención marco y definición de medidas internacionales. En 1983 se establece la Comisión Mundial para el Medio Ambiente y el Desarrollo de las Naciones Unidas, presidida por Gro Harlem Brundtland y, en 1987, se presentó el reporte denominado Our Common Future, en el cual por primera vez se define el concepto de desarrollo sostenible entendido como aquel que "satisfaga las necesidades del presente sin comprometer la capacidad de las futuras generaciones para satisfacer las propias" (BRUNDTLAND, 1987, p.23).

Dicho concepto se retoma en la Conferencia de las Naciones Unidas sobre el Ambiente y el Desarrollo (UNCED), realizada entre el 3 y el 14 de junio de 1992 en Río de Janeiro (Brasil), en la cual se definen distintas bases de acción; destacándose, en especial, la declaración sobre ambiente y desarrollo; la Agenda 21, que contiene 115 recomendaciones promoviendo la preservación del ambiente; y la Declaración de principios relativos a los bosques. Frente a estas iniciativas, una de las principales contribuciones radica en el esfuerzo por conciliar estrategias a través de acuerdos internacionales sobre la protección del ambiente (MOMTAZ, 1996); como, por ejemplo, la apertura de la Convención Marco de las Naciones Unidas sobre el Cambio Climático (CMNUCC). Justamente sobre dicha convención se conduce en diciembre de 1997 en Kyoto (Japón) a su aprobación en el denominado Protocolo de Kyoto4.

El nuevo milenio trae nuevas reflexiones en torno al ambiente y su sostenibilidad, así como también nuevos compromisos y acuerdos. Por ejemplo, la Cumbre mundial sobre Desarrollo Sostenible

\footnotetext{
${ }^{3}$ La conferencia también establece el Consejo de Administración del Programa de las Naciones Unidas para el Medio Ambiente (PNUMA); el Fondo para el Medio Ambiente y la Junta de Coordinación para el Medio Ambiente.

${ }^{4}$ En el año 2012 se realiza la Enmienda de Doha al Protocolo de Kyoto, que consiste en un segundo período de compromiso (previsto entre 2013 y 2020)
} 
realizada en Johannesburgo en 2002; y, en 2012, la Conferencia de Naciones Unidas sobre Desarrollo Sostenible (UNCSD) conocida como Río+20. Asimismo, en diciembre de 2015, las partes de la CMNUCC alcanzan el denominado Acuerdo de París, un tratado internacional sobre el cambio climático y que tiene como objetivo principal limitar el calentamiento global. También en 2015 el Papa Francisco publica su segunda encíclica denominada Laudato Si, Sobre el cuidado de la casa común; en la cual expone diversos procesos e impactos del ambiente. Desde su primer capítulo desarrolla "Lo que le está pasando a nuestra casa", abordando temas como: Contaminación y Cambio Climático; La cuestión de Agua; la Pérdida de la Biodiversidad; el Deterioro de la calidad de la vida humana y la degradación social (FRANCISCO, 2015).

En el año 2016, en Quito (Ecuador) se desarrolla la tercera conferencia de las Naciones Unidas sobre la vivienda y el desarrollo urbano sostenible, denominada Habitat III, en la misma, partiendo de las definiciones y postulados de las dos conferencias anteriores ${ }^{5}$, se retoman las problemáticas actuales que requieren una Nueva Agenda Urbana que "representa un ideal común para lograr un futuro mejor y más sostenible" (NACIONES UNIDAS, 2017, p. IV), articulando la nueva agenda con la Agenda 2030 para el Desarrollo Sostenible, aprobada en 2015 por los 193 Estados miembros de las Naciones Unidas. En este sentido, su aplicación contribuye a la implementación y consecución de los 17 Objetivos de Desarrollo Sostenible (ODS) de la Agenda 2030, focalizando, en especial, en el ODS 11 que propone "lograr que las ciudades y los asentamientos humanos sean inclusivos, seguros, resilientes y sostenibles" (NACIONES UNIDAS, 2017, p. 4).

Los avances en agendas, acuerdos y tratados, acordados a escala global, tienen sus implicancias en los diversos contextos locales de cada rincón del planeta. La planificación urbano-territorial incorpora en cada ámbito específico, según sus propias particularidades, nuevos objetivos y estrategias para lograr hábitats más sostenibles y resilientes. En este contexto, aquellos territorios íntimamente vinculados con el agua realizan así, diversas intervenciones y proyectos en sus frentes costeros, desde una nueva relación con dicho componente, y también desarrollan instrumentos de planeamiento y ordenamiento territorial. Especialmente desde fines el siglo XX se llevan a cabo numerosos planes parciales de reconversión de sectores obsoletos en nuevos espacios públicos junto al agua. Sin embargo, si bien estos proyectos se inician a través de planes de escala intermedia, con el objeto de reconvertir sectores estratégicos, rápidamente las distintas ciudades y regiones avanzan en una mirada amplia de sus frentes fluviales. Es ejemplo de ello la ciudad de Nueva York que, con más de 830 km de costa, inicia en 1982 un programa local de revitalización (ampliado a un plan general en 1992 que abarca la totalidad del frente costero de

\footnotetext{
${ }^{5}$ La primera conferencia sobre asentamientos urbanos de la ONU fue realizada en Vancouver (Canadá) en 1976, veinte años después se realiza la segunda conferencia (Hábitat II) en Estambul (Turquía), en la cual se realiza la Declaratoria de Estambul con el objetivo de lograr asentamientos urbanos sostenibles y con vivienda digna para todos. Se aprobó en dicha conferencia el Programa de Hábitat y los gobiernos se comprometieron a cumplir los objetivos consensuados a través de la Declaración de Estambul.
} 
la ciudad). Las actualizaciones continúan en los años siguientes, llegando a presentar en 2011 el New York City Comprehensive Waterfront Plan: Vision 2020, proponiendo ser revisado y ajustado cada 10 años, a fin de lograr que todo el frente fluvial de la ciudad sea más saludable, accesible y resiliente.

Otras ciudades norteamericanas que abordan diversas estrategias de planeamiento sostenible de sus costas son, por ejemplo, Boston (que incorpora su Waterfront en el eje de Cambio Climático y planeamiento ambiental, mediante distintos instrumentos intermedios sectorizados); Chicago (a través del diseño urbano de los márgenes del lago Michigan y el río Chicago, generando espacios públicos sostenibles). También así, Canadá presenta en distintas ciudades instrumentos de planeamiento de espacios de interfaz entre tierra y agua, como por ejemplo el Waterfront Toronto (creado originalmente en 2001), que aborda más de 800 hectáreas de suelo propuesto para su rehabilitación, conformado con diversos proyectos estratégicos a corto y mediano plazo (BUNCE, 2009). Los Países Bajos resultan un ejemplo significativo de sinergia entre articulación de tierra y agua, con identidad particular a lo largo de su historia, generando nuevos espacios firmes por sobre cuerpos de agua. Por lo cual, el abordaje de sus frentes costeros en materia de planeamiento presenta varias décadas de existencia. Ciudades como Ámsterdam, Rotterdam y Maastrich registran una larga trayectoria de planificación en torno a la revitalización de sus waterfronts, integrando tanto las distintas escalas como a través de diversos usos y actividades (MCCARTHY, 1996). (Figura 1)

Figura 1. Arriba: Transformaciones del waterfront de Nueva York: Waterfront Plan 2020, Battery Park y Brooklyn Bridge Park. Debajo: Lakefront de Chicago y Riverfront de Rotterdam (Kop Van Zuid).

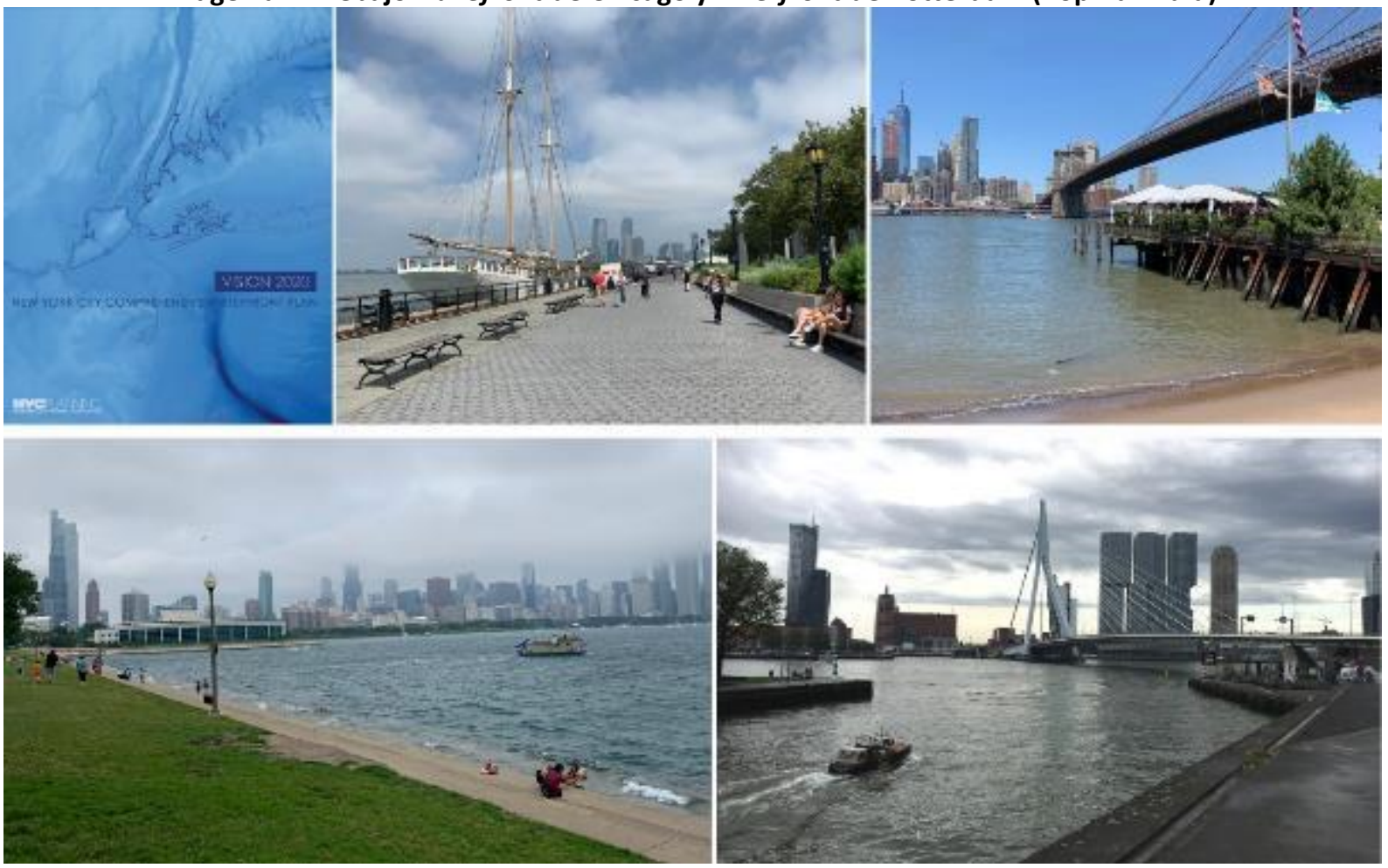

Fuente: www1.nyc.gov y fotografías del autor. 
De este modo, el rol de la matriz fluvial en el planeamiento se encuentra presente en distintos países y escalas de actuación. En Latinoamérica, se reconocen diversos planes e iniciativas, como por ejemplo, el Plan de Desarrollo 2020-2023 de Barranquilla (Colombia), que incorpora el apartado “Medidas frente al cambio climático" y el reto "Soy Biodiverciudad" en el que se propone principalmente "involucrar a la ciudadanía en la conservación de los ecosistemas y el desarrollo sostenible de la ciudad" (ALCALDíA DE BARRANQUILLA, 2020, p.333) reconociendo la particular biodiversidad de sus cuerpos de agua que "propician la adaptabilidad del cambio climático". En Buenos Aires (Argentina), se destaca que en el 2008 se aprueba el Plan Urbano Ambiental (proceso iniciado en 1998), a fin de asegurar una mayor calidad ambiental y bienestar de la población. Su actualización, actualmente en curso se vincula a los ejes físicosterritoriales de la Agenda 2030 y los 17 ODS sobre los que la Ciudad de Buenos Aires trabaja desde el 2016 (CONSEJO DEL PLAN URBANO AMBIENTAL, 2020; CIUDAD DE BUENOS AIRES, 2020).

\section{LA MATRIZ FLUVIAL EN LA PLANIFICACIÓN DEL ORIGINAL “PAGO DE LOS ARROYOS”.}

El Área Metropolitana de Rosario se caracteriza por una compleja matriz fluvial. Este territorio desde mediados del siglo XVI era conocido como Pago de los Arroyos, debido al extenso frente ribereño del río Paraná y a los numerosos cursos de agua que incorporaba su delimitación inicial (entre el río Carcarañá y la Cañada de las Hermanas), los actuales arroyos: San Lorenzo, Ludueña, Saladillo, Frías, Seco, Pavón, del Medio y Ramallo6; junto a una gran cantidad de cañadas, humedales, bajíos, entre otros componentes, que conforman una valiosa dinámica hídrica (MONGSFELD, 1983). (Figura 2)

Figura 2. Matriz fluvial del Área Metropolitana de Rosario.

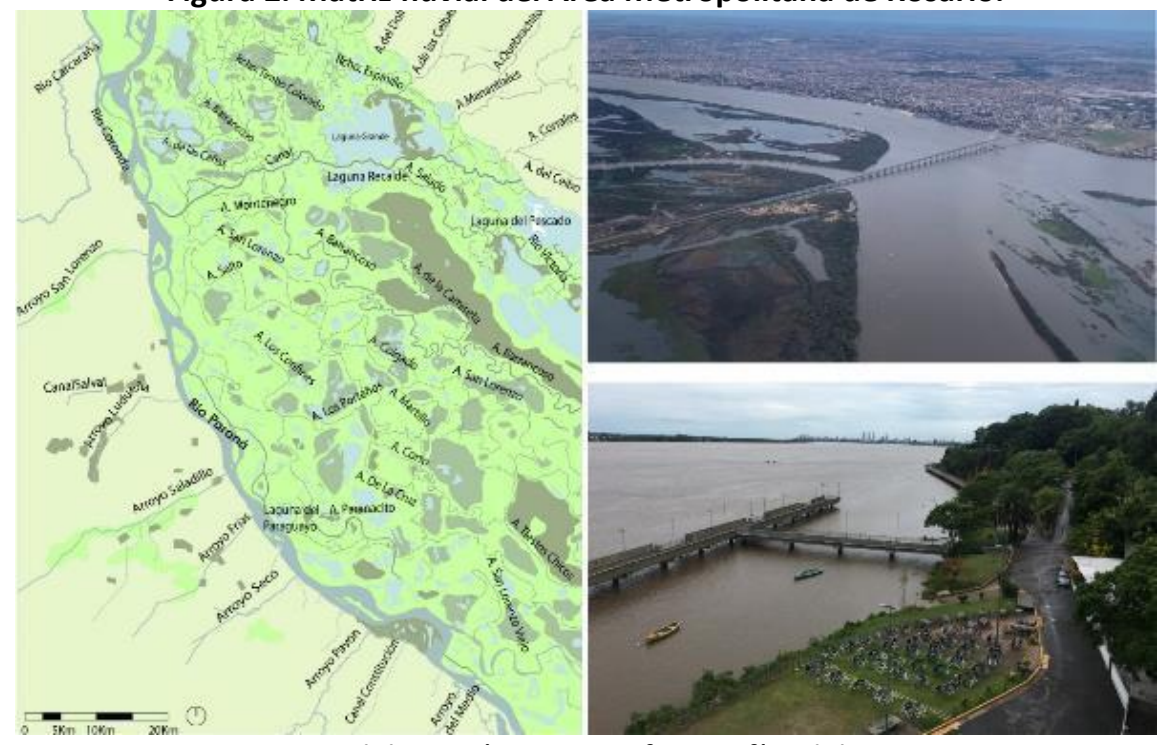

Fuente: Elaboración propia y fotografías del autor.

\footnotetext{
${ }^{6}$ Es importante destacar que la delimitación original del Pago de los Arroyos, además del actual ámbito del AMR, también incluía los partidos de San Nicolás y de Ramallo. El componente fluvial era tan representativo que, Rosario al comenzar con su proceso de poblamiento llevó como nombre completo "Rosario de los Arroyos"; sin embargo, en la actualidad, sólo mantiene dicho nombre San Nicolás de los Arroyos (MIKIELIEVICH, 1973)
} 
Estas características han posibilitado a la región posicionarse desde sus inicios como un área productora agrícola-ganadera; así como las condiciones de barranca y navegabilidad del Paraná, conducen a conformar un polo portuario de gran relevancia. De manera que, desde mediados del siglo XIX, en Rosario se realizan numerosas intervenciones sobre la línea de ribera a fin de ganar tierras al río para las actividades ferro-portuarias. Sin embargo, el primer Plan Regulador y de Extensión de Rosario presentado en 1935, desde una perspectiva higienista y con el objetivo principal de saneamiento urbano, propone una profunda transformación de la costa central de la ciudad, trasladando al norte y al sur las infraestructuras productivas, a fin de generar nuevos espacios públicos. Asimismo, se plantea la generación y resguardo de grandes espacios verdes junto a los componentes hídricos, como la transformación de las cuencas de los arroyos Ludueña y Saladillo como zonas verdes para deportes y esparcimiento. También establece un sistema de parques a nivel regional, mayormente vinculados a los cursos de agua, proponiendo como zonas verdes: el área boscosa junto al Paraná en la actual localidad de Capitán Bermúdez; el sector forestado de las barrancas de la localidad de Alvear; y, a fin de invertir la situación del Paraná "siempre tan ajeno a la vida de la población rosarina", también plantea "humanizar" la isla del Espinillo, principalmente, en espacios verdes recreativos y deportivos" (DELLA PAOLERA, GUIDO, FARENGO; 1935, p.52).

Si bien por diversos motivos estas iniciativas no llegan a materializarse prontamente, sí permanecen vigentes, en su gran mayoría, en los postulados de los siguientes planes reguladores de Rosario. El Plan Rosario de 1954 reitera la liberación de las barrancas del río Paraná de instalaciones productivas en su costa central para la generación de nuevos espacios libres, así como el saneamiento de las cuencas de los arroyos Ludueña y Saladillo (MONTES, 1964). A pesar de los cambios gubernamentales y políticos, estas propuestas persisten también en el Plan Regulador de 1968, insistiendo en la necesidad de trasladar las infraestructuras portuarias hacia el sur de la ciudad y se proponen nuevos centros de recreación y esparcimiento a fin de recuperar las "energías físicas e intelectuales de la población mediante la contemplación de la naturaleza, el ejercicio corporal, las manifestaciones artísticas y la participación pasiva en las actividades elegidas" (MUNICIPALIDAD DE ROSARIO, 1967, p.22); siendo, para ello, los espacios junto al agua los sectores elegidos para su desarrollo: Paseo Ribereño, Parque Arroyo Ludueña, Parque Sur (comprende ambas márgenes del Arroyo Saladillo), Parques Belgrano y Urquiza, Parque a la Bandera, entre otros.

Por otra parte, las propuestas vinculadas a una mayor relación entre los ciudadanos y sus cursos de agua también están presentes a nivel regional a través del Organismo de Prefectura del Gran Rosario que, en su Plan Orgánico para el área, plantea tanto en el sector norte como en el sur de la región una mayor conexión con el río Paraná a través de la creación de nuevas avenidas urbanas de interconexión entre las áreas urbanas y el Paraná, como también se proponen nuevos sectores de áreas verdes y 
recreación junto al río en las localidades costeras de la actual AMR (ANSALDI, COREA Y PLA, 1972). Sin embargo, a pesar de las numerosas propuestas, son escasas las intervenciones efectivamente materializadas; siendo frecuente a lo largo de gran parte del siglo XX la persistencia de representaciones e imaginarios que reclaman haber crecido de espaldas al río. No obstante, desde mediados la década de 1980 se reconoce una nueva etapa, a través de la cual se cristalizan gran parte de las mencionadas propuestas.

La Actualización del Plan Regulador y Bases Documentales para la revisión del Código Urbano (iniciado con estudios preliminares en 1985 y presentado en 1991) marca una nueva etapa del planeamiento rosarino; retomando gran parte de los temas estructurales de la ciudad propuestas desde 1935 (como la recuperación de la costa y el saneamiento de los arroyos). Este documento "reivindica el rol público del sistema costero como área recreativa y turística de carácter micro-regional" (MUNICIPALIDAD DE ROSARIO, 1991, p.9); para lo cual, elabora diversas acciones concretas a corto, mediano y largo plazo, a fin de incrementar el verde urbano y los espacios libres de la ciudad, en sus diversas escalas ${ }^{7}$. En la década de 1990 se concretan acciones que definen la esperada interconexión de la ciudad con el río; como la apertura de avenidas ribereñas, la inauguración del Complejo del Parque España de Rosario (1992), la restauración de componentes patrimoniales ferro-portuarios para nuevos usos (mayormente públicos, culturales y recreativos), entre otros. También así, se registra una mayor vinculación entre el Paraná y el delta con los habitantes, incrementado notablemente las embarcaciones vinculadas al ocio y la gran cantidad de visitantes en las islas frente a la ciudad. De este modo, ya se vislumbra un cambio del imaginario de una ciudad que creció de espaldas a dar la cara al río ${ }^{8}$.

El primer Plan Estratégico de Rosario, presentado en 1998, establece como uno de sus objetivos generales:

Articular la ciudad con el río y las islas, promoviendo una transformación urbanístico-ambiental que siente las bases de un modelo de desarrollo sustentable y consolide una nueva imagen de Rosario (MUNICIPALIDAD DE ROSARIO, 1998, p. 84).

El sistema ciudad-río también se posiciona en uno de los proyectos estructurales de la actualización del Plan Director presentado en 1999, incorporando, a su vez, la atención a la "preservación del medio ambiente y del patrimonio construido", a través de diversas estrategias e instrumentos de

\footnotetext{
${ }^{7}$ Se incorpora, además, el concepto de "sistema ecológico general", que especialmente se enfoca al saneamiento, gestión de residuos, incorporación de normativas de contaminación y actualización de la información de las condiciones del medio ambiente de Rosario y su conurbación metropolitana (MUNICIPALIDAD DE ROSARIO, 1991, p.30).

${ }^{8}$ Dicho cambio es tan rotundo, que por ordenanza 6.200 de 1996 se crea el Ente de Turismo de Rosario (ETUR), quedando implementado en 1997. Justamente desde su inicio, el Paraná, la costa y el delta se posicionan en los principales polos atractores turísticos de la ciudad.
} 
protección ambiental, como, por ejemplo, definiendo "Áreas de protección ambiental" al frente litoral del Paraná, las islas del alto delta y los grandes parques regionales en torno a cursos de agua como los localizados en la cuenca del Ludueña (Bosque de los Constituyentes) y en la cuenca del Saladillo (Parque Regional sur y ambas márgenes del arroyo en su extensión municipal). (Figura 3)

Figura 3. La preservación del patrimonio ambiental de Rosario y su región y "Sistema ciudad-río" como proyecto estructural del Plan Director de Rosario. Bases para el Acuerdo.

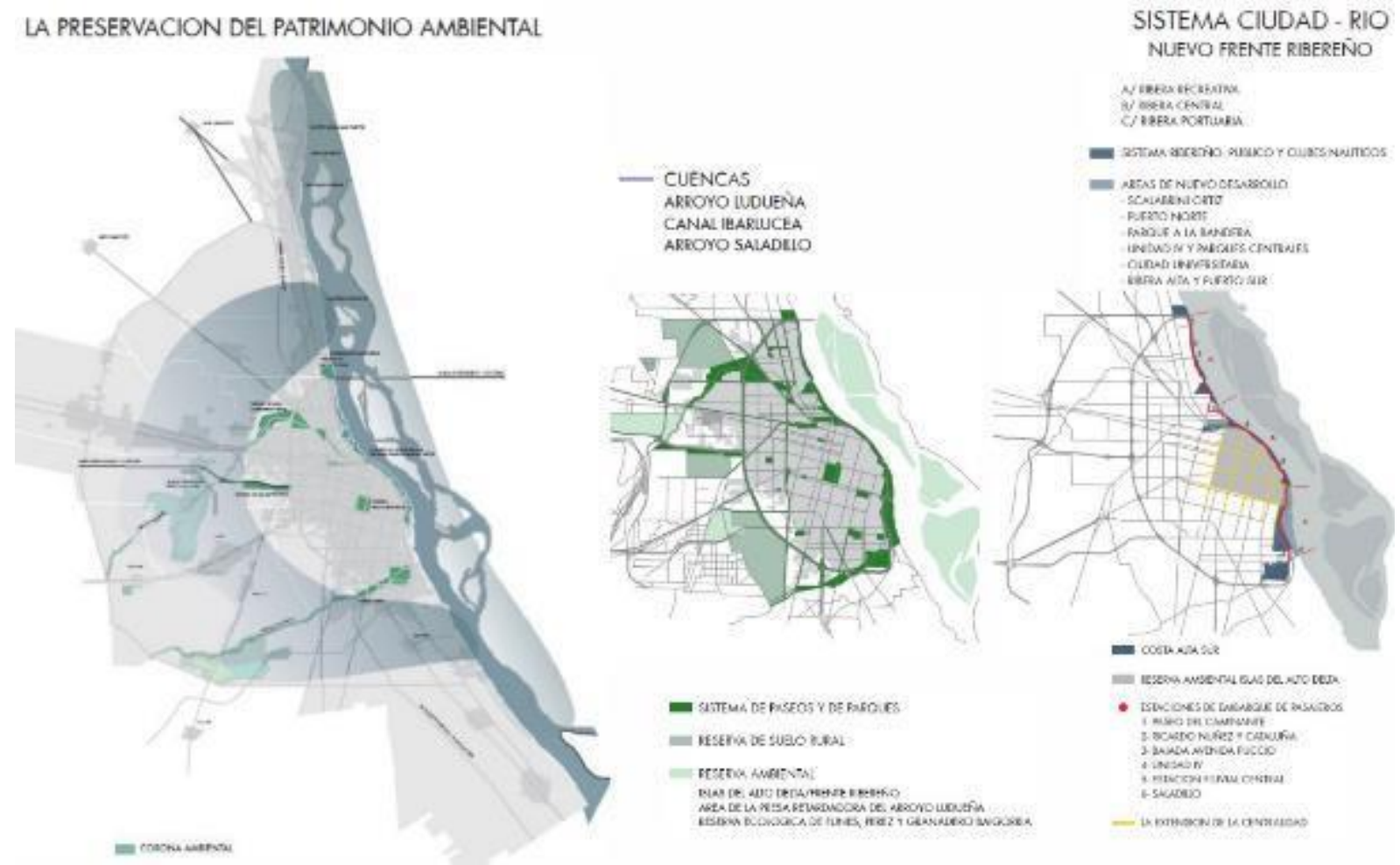

Fuente: Municipalidad de Rosario (1999).

\section{Nuevas perspectivas del planeamiento urbano-territorial del AMR: propuestas y desafíos}

El cambio de siglo trae consigo la inauguración de numerosas obras que posibilitan una nueva relación entre la sociedad y su patrimonio ambiental y cultural, a través de la generación de nuevos parques en la costa central junto a la rehabilitación de componentes de infraestructuras ferro-portuarias desafectadas. Asimismo, la inauguración del puente Rosario-Victoria en 2003 posibilita nuevos modos de conexión rápida, no solo con la otra orilla del Paraná, sino también con su delta (Figura 4). Es así, que gran parte de los habitantes de la región establecen frecuentemente nuevas actividades íntimamente asociadas a la matriz fluvial; lo que conduce, a su vez, al desarrollo de una mayor conciencia sobre la importancia y la necesidad de su resguardo y preservación. 

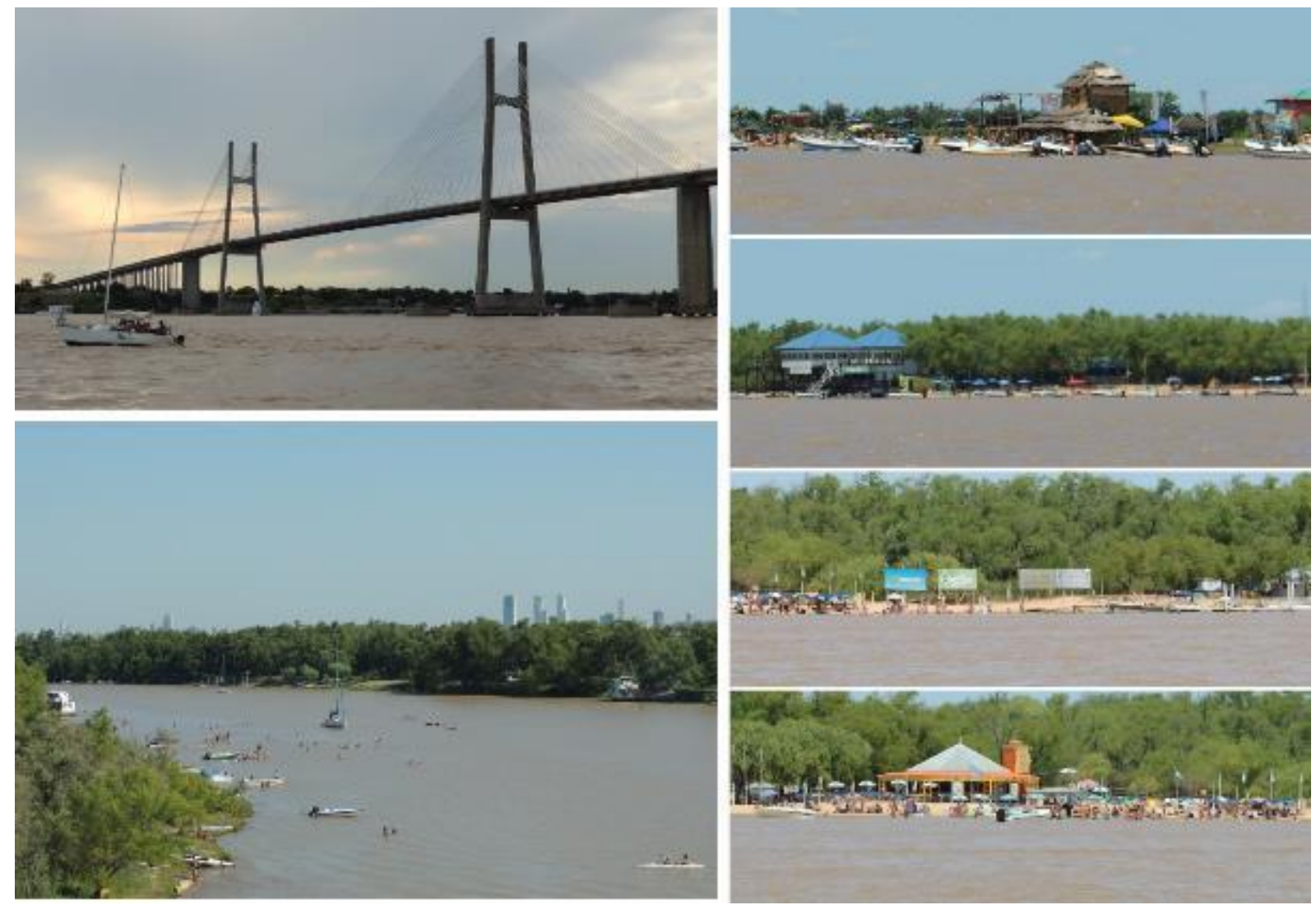

Figura 4. Puente Rosario-Victoria y nuevas apropiaciones de la matriz fluvial de Rosario y su región. Fuente: Fotografías del autor.

Dicho interés tiene su correlato en la actualización del Plan Urbano de Rosario (2007-2017), en el cual se incorpora al ambiente como temática sectorial clave, planteando que dicho plan y su conjunto normativo tienen como objetivo último "garantizar un desarrollo sustentable y equilibrado de la ciudad poniendo énfasis en el cuidado de los recursos naturales, para el disfrute de la población actual, y de las generaciones futuras"; como también avanza sobre los recursos ambientales de relevancia regional, indicando que

se deberá impulsar un trabajo conjunto con los municipios y comunas del área y con el gobierno provincial estableciendo acuerdos para el manejo de recursos compartidos (sean de carácter natural paisajístico o cultural) ${ }^{9}$ (MUNICIPALIDAD DE ROSARIO, 2011, p. 66) (Figura 5).

\footnotetext{
${ }^{9}$ Es importante destacar, que en la primera década del siglo XXI también se desarrollan otros proyectos, propuestas e intervenciones vinculadas a la matriz fluvial en el AMR, por ejemplo, en el 2007 desde la entonces Oficina de Asuntos Metropolitanos (AOM) de la Provincia de Santa Fe se presentan los Planes de Ordenamiento territorial de la Costa Metropolitana del Gran Rosario: Cordón Norte y Cordón Sur, así como sus respectivos Inventarios del Patrimonio Natural y Construido; y, en el 2009, se inaugura la costanera de la ciudad de San Lorenzo, generando un nuevo balcón al río para la ciudad, en contigüidad al Campo de la Gloria y el Convento de San Lorenzo, componentes clave de la historia local, regional y nacional.
} 
Estas iniciativas se profundizan a través de nuevas acciones, especialmente en la última década (período 2010-2020), a través de estrategias de planeamiento, proyecto, gestión e intervención, a fin de posibilitar una región metropolitana más sostenible.

Figura 6. Sistemas e infraestructuras ambientales de Rosario y su Área Metropolitana.

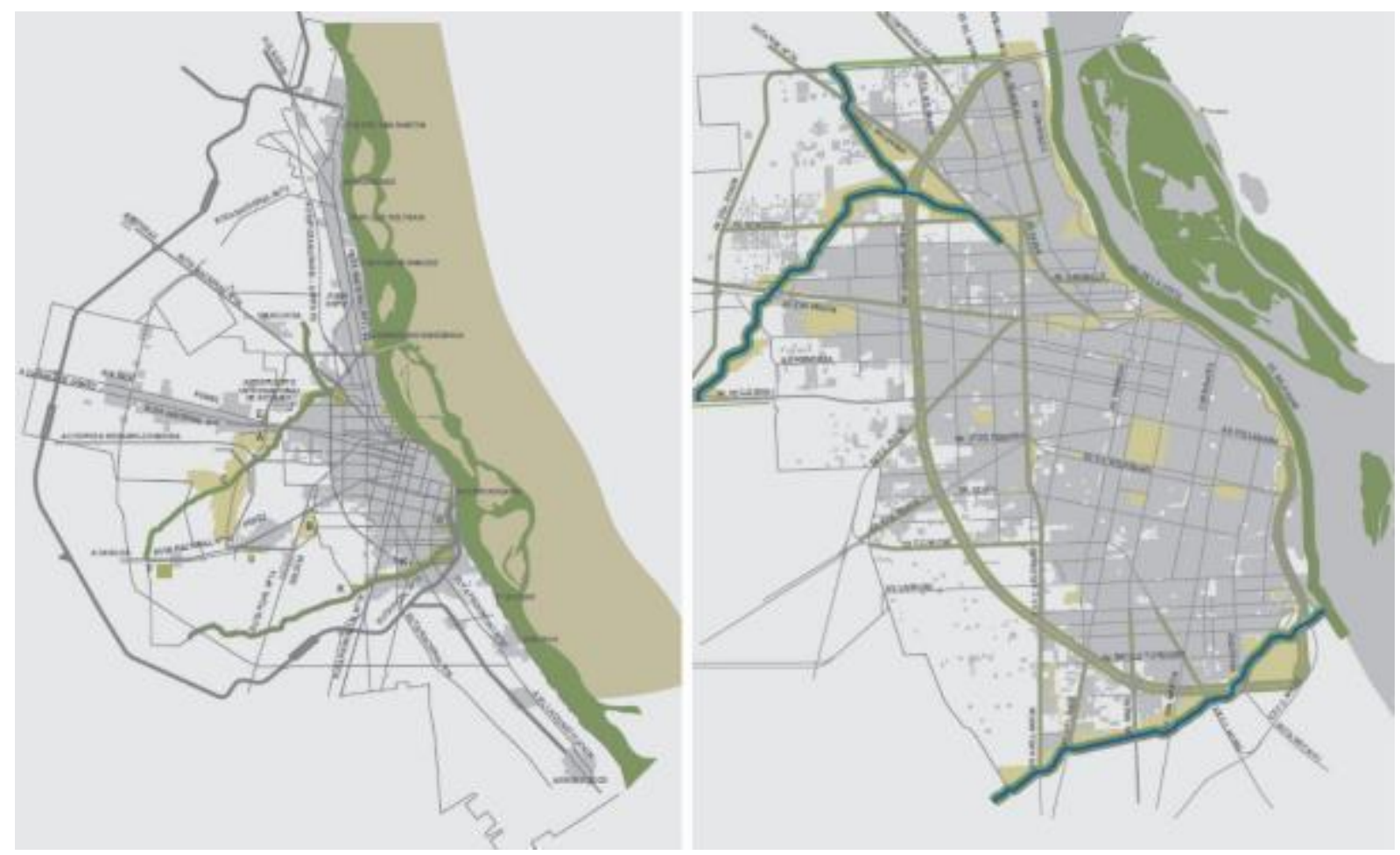

Fuente: Municipalidad de Rosario (2011).

Con la creación del Ente de Coordinación Metropolitana de Rosario (ECOMR) se desarrollan nuevos acuerdos y consensos que sintetizan un modelo territorial deseado para el AMR, definido a través de siete Directrices de Ordenamiento Territorial. Justamente, dos de estas directrices, se enfocan en la protección y optimización de los recursos ambientales y patrimoniales; así como la mejora en las condiciones de saneamiento ambiental para toda el área. En ambas se parte del carácter estructurante de su matriz fluvial, sus dinámicas hídricas, ecosistemas naturales y una biodiversidad muy particular del litoral que "han sido modificados notablemente en los últimos años, dejando lugar a núcleos ecológicos diferenciados debido a la presión de los procesos de urbanización, en especial, la ocupación del área ribereña" (FEIN, 2014, p.37). En este sentido, se proponen diversos objetivos a fin de reducir los impactos sobre los cursos de agua y sus márgenes, en especial del Paraná, garantizando "el acceso a los servicios ambientales y usos recreativos de la ribera" (FEIN, 2014, p.37). Estas directrices definidas a nivel general, se desarrollan en las distintas escalas, dado que también se estudia de manera particularizada cada corredor o cuadrante del área y en cada ámbito local. (Figura 6) 
Figura 6. Protección de los recursos ambientales y patrimoniales según DOT y Sistema Ambiental Integrado por corredor/cuadrante del AMR.
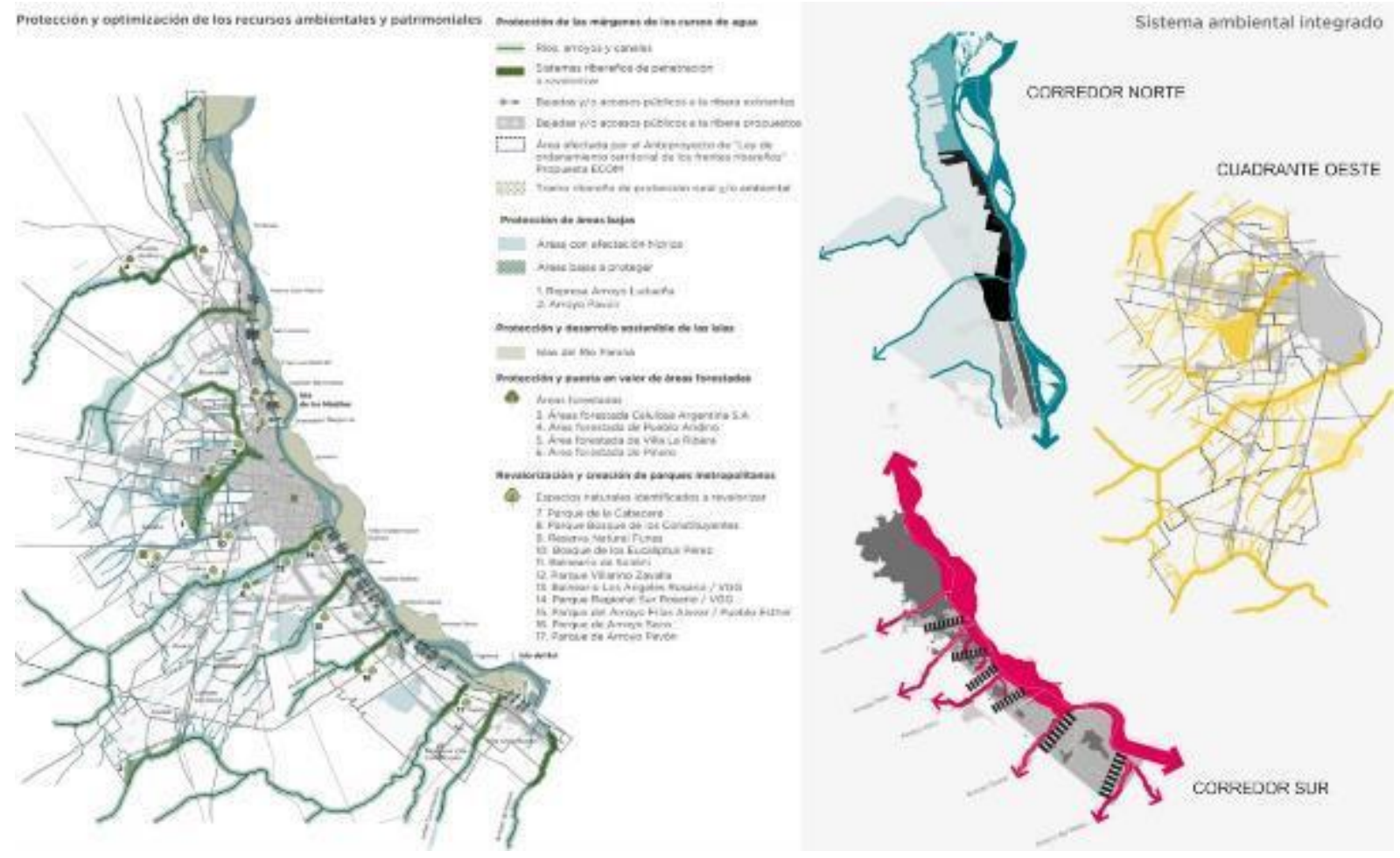

Fuente: ECOMR (2018, 2019a y 2019b).

En dicho contexto, también la ciudad cabecera del área, Rosario, presenta el Plan Estratégico 2030 y el documento base de actualización del Plan Urbano 2030. En ambos se posiciona al "hábitat de calidad, sostenible y resiliente" como objetivos principales para la ciudad en las próximas décadas. En este sentido, mientras el plan urbano avanza sobre definiciones y proyectos territoriales de sostenibilidad ambiental, recuperación y protección de los cursos fluviales, el incremento de espacios verdes y corredores ecológicos, en especial "en torno a los arroyos Saladillo y Ludueña y a la integración del sistema ribereño y la protección de humedales del delta del Paraná" (MUNICIPALIDAD DE ROSARIO, 2019, p.14); el plan estratégico incorpora diversas estrategias vinculadas al turismo sostenible, incremento de energías limpias, mayor participación ciudadana en el desarrollo sostenible de la ciudad, a fin de lograr una "ciudad sustentable con biodiversidad y cursos de agua preservados" (MUNICIPALIDAD DE ROSARIO, 2018, P.86).

Todos estos documentos (Planes Urbanos Locales y Plan Estratégico) prevén como plazo temporal el año 2030, justamente se encuentran en concordancia con la Nueva Agenda Urbana 2030 de las Naciones Unidas para el Desarrollo Sostenible (NACIONES UNIDAS, 2017). Asimismo, frente a este pacto global de Hábitat III que propone una mayor sostenibilidad a través de los ODS y sus respectivas metas; la 
Municipalidad de Rosario ${ }^{10}$ en el 2016 presenta el Plan Ambiental Rosario. Este documento aborda la perspectiva metropolitana a través de una convocatoria amplia de actores:

incluye las políticas y estrategias locales que consolidan la integración de la variable ambiental en la planificación y gestión de la ciudad, e impulsa proyectos estratégicos para los próximos años que aseguren la preservación de los recursos y la calidad de vida para las personas, en una ciudad que conserve su escala humana. (MUNICIPALIDAD DE ROSARIO, 2016, p.40).

El Plan Ambiental propone seis ejes de actuación ${ }^{11}$, de los cuales uno de ellos se denomina "Cursos de agua y biodiversidad". A través del cual se desarrolla la relevancia de la matriz hídrica regional, proponiendo nueve lineamientos estratégicos, siendo los dos primeros: 1. Río Paraná y Humedales; y, 2. Recuperación integral de los arroyos Ludueña y Saladillo. El resguardo de estos sectores, como hemos visto en el apartado anterior, se postula desde las primeras décadas del siglo XX, sin embargo, la perspectiva higienista inicial que motorizaba dichas propuestas, en el siglo XXI cambia por una nueva mirada que plantea la necesidad de la protección ambiental y su sostenibilidad. (Figura 7)

\section{Figura 7. Plan Ambiental de Rosario y objetivos de preservación de la matriz ambiental de la ciudad y} su región.
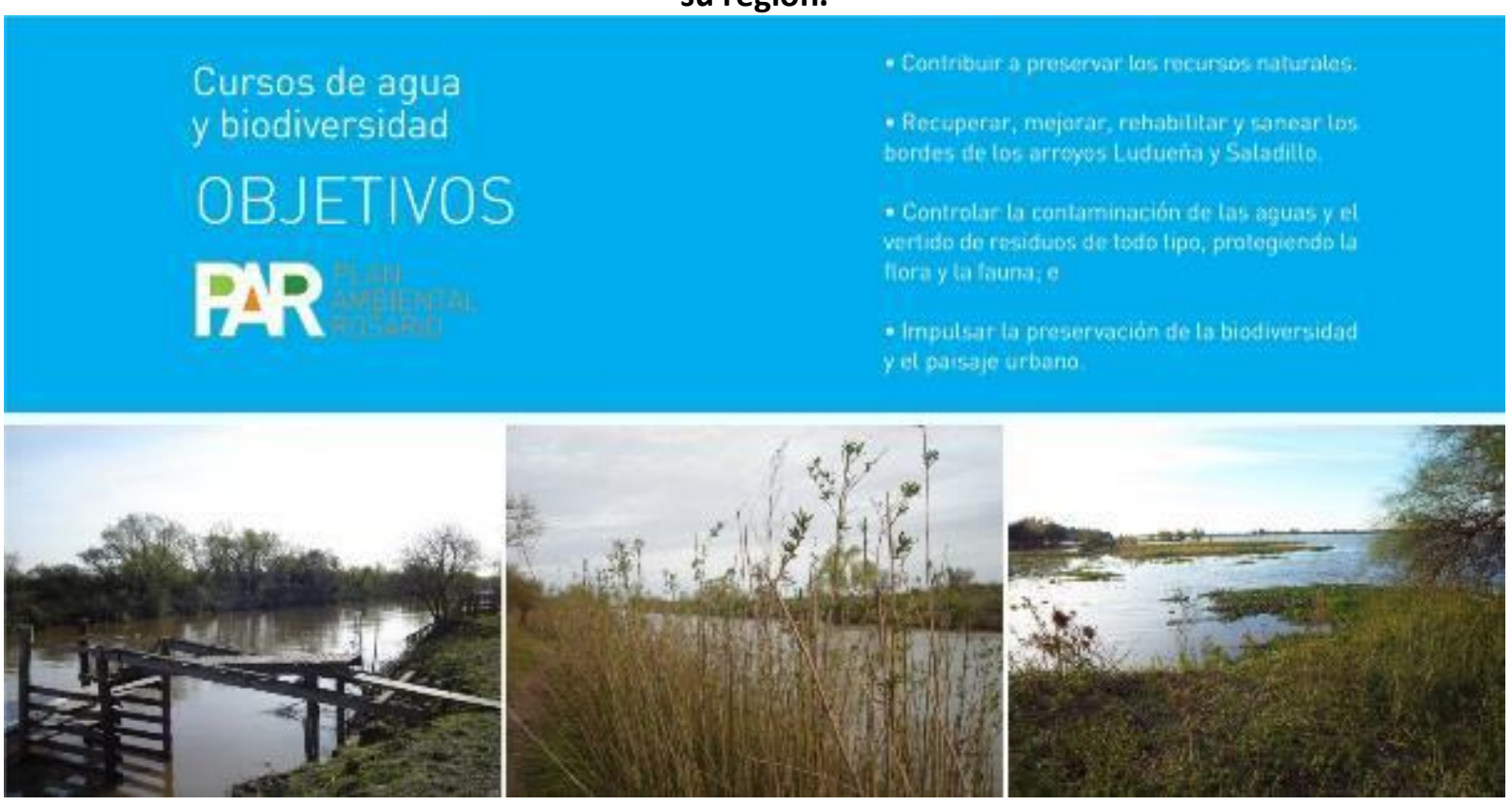

Fuente: Municipalidad de Rosario (2016) y fotografías del autor.

\footnotetext{
${ }^{10}$ Es importante destacar que, el capítulo 6 del Plan Estratégico 2030 se dedica a la Agenda Global 2030, a través de la definición del compromiso local en la Agenda Local y los 17 ODS como guías de las estrategias para la ciudad de Rosario, junto a la definición de un sistema de indicadores como plataforma de seguimiento de los objetivos de cada estrategia (MUNICIPALIDAD DE ROSARIO, 2018, pp. 124-139).

${ }^{11}$ Los seis ejes de actuación del Plan Ambiental de Rosario son: 1. Residuos Sólidos Urbanos; 2. Gestión ambiental en las actividades productivas y producción + limpia; 3. Cambio climático y energía; 4 . Calidad de aire y ruido; 5. Cursos de agua y biodiversidad y 6. Ciudadanía ambiental.
} 
Entre los proyectos estratégicos que se plantean para el primer punto, se destaca la creación de un área de conservación en el territorio insular de 600 hectáreas de las 2.204 que pertenecen a la Municipalidad de Rosario en dicho ámbito geográfico. Se desarrolla así, la Reserva Los Tres Cerros con el objetivo principal de establecer un área de conservación y observación de la biodiversidad de los humedales del delta. Esta reserva resulta un ámbito educativo, científico y de ecoturismo sostenible que promueve diversas acciones para profundizar el conocimiento sobre la riqueza del ambiente, de la historia y las culturas regionales de la población isleña; así como promover estrategias para su preservación. Por otra parte, el Plan Ambiental de Rosario también define directrices para la preservación ambiental de los bordes del Paraná, como también propone un plan integral de ordenamiento de los frentes ribereños presentes en toda el AMR.

A pesar de estos documentos, proyectos y directrices de actuación, en los últimos años, la matriz fluvial del AMR están sujetos a profundos impactos y problemáticas que han ocasionado grandes pérdidas de biodiversidad, poniendo en riesgo su rol ecosistémico. Por un lado, se registra una aceleración de procesos de urbanización en sectores costeros que han tendido a cambios de relevancia de la topografía de barrancas, eliminando a su vez, bajíos y sectores de humedales, así como también transformando las dinámicas hídricas (por ejemplo, ante la realización de caletas para embarcaciones náuticas o construcciones que modifican notoriamente la topografía ribereña). Asimismo, la realización de canalizaciones ilegales por privados (a fin de cambiar las dinámicas hídricas para beneficios vinculados a la producción agrícola), junto a nuevos modos de producción y la realización de urbanizaciones en sectores anegables han ocasionado grandes impactos en el territorio, modificando la impermeabilización del suelo y el escurrimiento natural de las aguas.

Por otra parte, en los últimos años se han profundizado las quemas en el delta del Paraná (por el desplazamiento de actividades como la ganadería en el ámbito insular) ${ }^{12}$. Especialmente desde el 2008 , las prácticas ilegales de quemas de vegetación original del delta comenzaron a ser más frecuentes e intensivas, llegando a generar graves efectos al hábitat regional en su conjunto, llegando a perderse más de 170.000 hectáreas por el fuego en dicho año. Por esto, se firma el Plan Integral Estratégico para la Conservación y Aprovechamiento Sostenible en el Delta del Paraná (PIECAS-DP), resultando un acuerdo interjurisdiccional entre las provincias de Santa Fe, Entre Ríos y Buenos Aires, junto al Gobierno nacional, a fin de gestionar la preservación de los humedales del delta del Paraná, a través de un uso sostenible. Sin embargo, a pesar de la constitución del PIECAS-DP, con un Acta Acuerdo reiterada y firmada entre las diversas jurisdicciones en 2014, en 2020 se incrementan vertiginosamente los focos de incendios, reiterados en todo el año. De manera que, entre enero y septiembre de 2020, según datos oficiales del

\footnotetext{
${ }^{12}$ Las prácticas ganaderas incorporan la quema de la vegetación autóctona a fin de preparar el terreno.
} 
Ministerio de Ambiente y Desarrollo Sostenible ${ }^{13}$, se estiman más de 328 mil hectáreas de delta destruidos. (Figura 8)

Figura 8. Izquierda arriba: PIECAS-DP 2008 y2014. Izquierda debajo: Incendios en el delta en 2020. Derecha: Áreas quemadas en el territorio definido por PIECAS entre enero y septiembre de 2020.
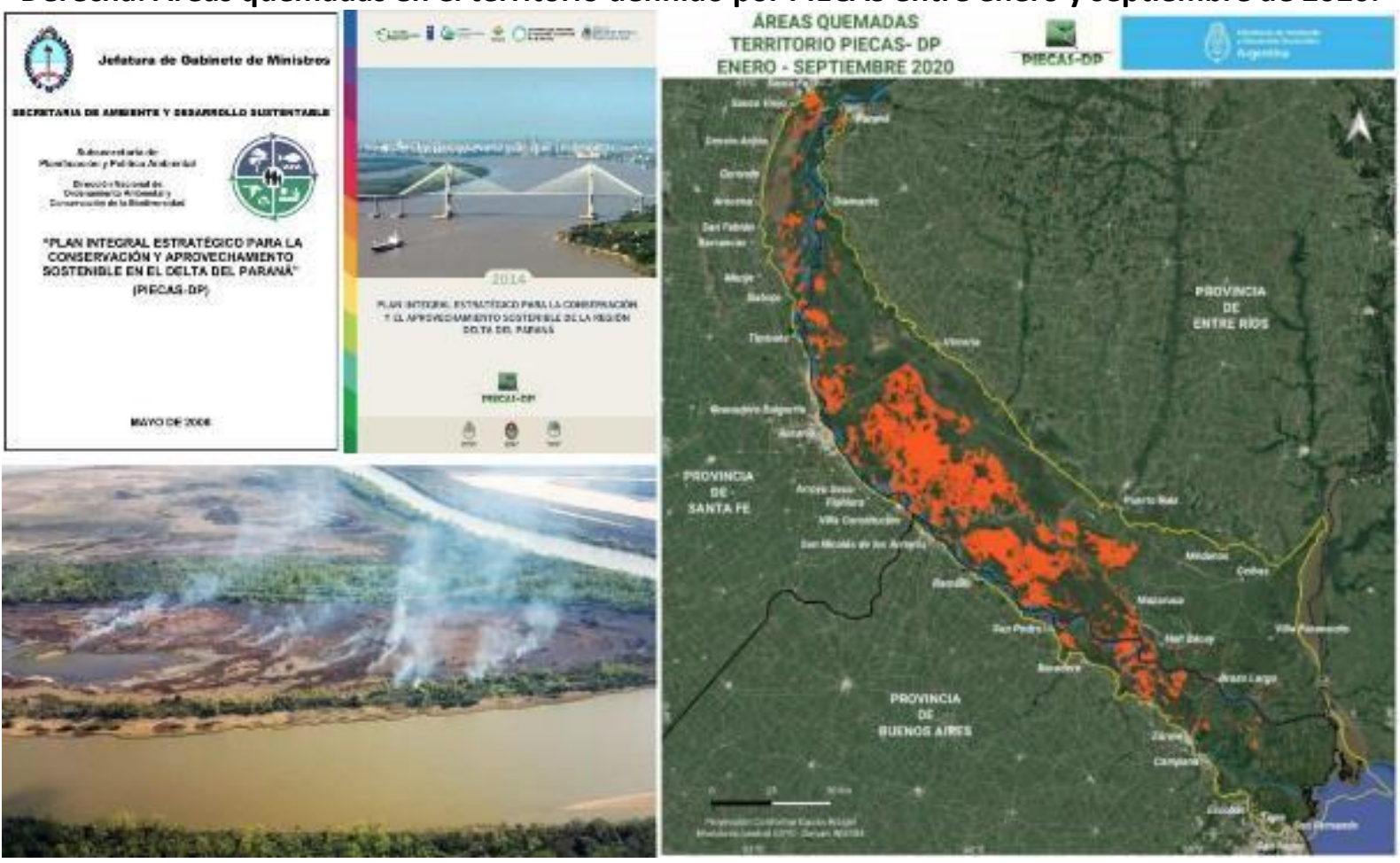

Fuente: Secretaría de Ambiente y Desarrollo Sustentable (2008 y 2014); analisisdigital.com.ar y Ministerio de Ambiente y Desarrollo Sostenible (2020).

Frente a la gravedad de las quemas, los profundos e irreparables impactos (como la muerte y pérdida de gran cantidad de flora y fauna, la alteración de la biodiversidad del delta, la destrucción de humedales y los problemas diversos que implica la persistencia de humo, con su alta contaminación de aire para las poblaciones aledañas, entre otras); se ha fortalecido la concientización y compromiso social por la importancia de la protección de la matriz fluvial de la región y su ambiente. En este sentido, han sido numerosos los reclamos de diversas organizaciones no gubernamentales como el Taller Ecologista y El Paraná No se toca, a los que se ha sumado la población de Rosario y su área metropolitana, junto a diversos sectores gubernamentales (en algunas acciones) a través de diferentes marchas, manifestaciones, actividades de divulgación y concientización, y de reclamos ante la justicia (Figura 9). Es así, que la gran cantidad de acciones internacionales que toman lugar desde las últimas décadas del siglo XX hasta la actualidad, junto a las diversas directrices locales, han posibilitado un nuevo contexto en el

\footnotetext{
${ }^{13}$ Según datos extraoficiales, de diversos Organismos No Gubernamentales, la cantidad de hectáreas de delta perdidos durante el 2020, superan las 400 mil (BARRANDEGUY, 2020).
} 
cual el ambiente ya no resulta una simple plataforma funcional; sino, se reconoce una profunda sinergia entre la matriz natural y los habitantes, los cuales reclaman el resguardo y conservación del ambiente.

Figura 9. Manifestaciones en $\mathbf{2 0 2 0}$ por las quemas en el delta del Paraná.
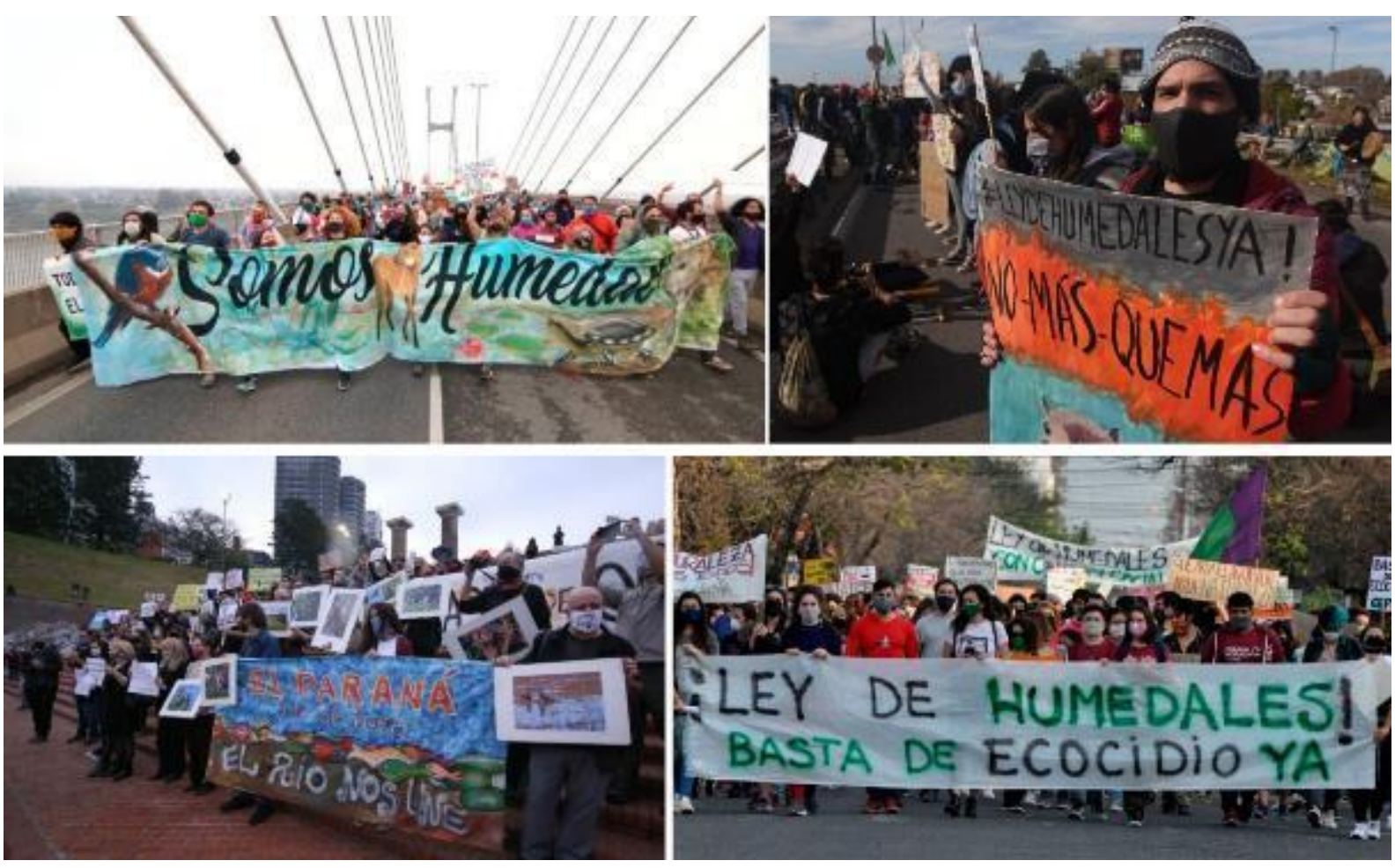

Fuente: www.anred.org; informedigital.com.ar; rosario3.com y elonce.com

\section{CONCLUSIONES}

El ser humano desde sus primeras acciones en el territorio ha generado impactos en el ambiente, como también así tiene conciencia de los efectos de sus intervenciones. No obstante, son relativamente recientes el reconocimiento extendido, la divulgación, los acuerdos y actividades a nivel global a fin de desarrollar hábitats integrales más sostenibles en el tiempo. En este sentido, especialmente desde la segunda mitad del siglo XX, comienzan a desarrollarse nuevas estrategias de planificación que parten del reconocimiento y análisis de la matriz ambiental, cuyos componentes se posicionen como la base indispensable del diseño urbano-territorial. Proyectar con la naturaleza, significa un cambio de mirada y de acción, tanto en el reconocimiento de la sociedad en general, como en la propia disciplina del planeamiento urbano-regional.

De este modo, las diversas operaciones llevadas a cabo desde distintos organismos internacionales han posibilitado con el transcurrir de las décadas la conformación de acuerdos, tratados y objetivos que conducen a agendas concretas y comunes de actuación entre diversos países. La 
articulación entre las definiciones y acuerdos globales con cada ámbito local ha fortalecido en los últimos años el desarrollo de instrumentos de planeamiento con foco en la protección y preservación del ambiente a través de nuevos vínculos y proyectos entre las actividades humanas y su entorno. Como se refleja en el sector territorial estudiado en el presente artículo, si bien el reconocimiento de la matriz fluvial del Área Metropolitana de Rosario se registra en su toponimia desde las primeras marcas del hombre europeo, como así también la atención a la generación de nuevo espacio libre en torno a los cursos fluviales desde sus primeros planes reguladores; es recién desde las últimas décadas del siglo XX que se desarrolla una nueva plataforma instrumental y de acción (vinculadas a las directrices internacionales) que abogan hacia un desarrollo sostenible del territorio.

Es así, que las acciones registradas en las últimas décadas han profundizado el vínculo entre los pobladores del AMR con su matriz fluvial, no solo como elemento identitario, sino como componente fundamental de su ambiente y hábitat cotidiano, que es necesario defender y preservar. Es por ello, que el reclamo inicial de recuperar los cursos fluviales, en especial el Paraná y su delta, para nuevas actividades recreativas y de acceso público (ya conseguido en gran medida en la primera década del siglo XXI), se transforma, en los años recientes, en el reclamo por la protección y resguardo de la amplia biodiversidad existente en este territorio del agua. De este modo, a pesar de los avances en materia de planeamiento urbano-territorial en la última década en torno a los diversos abordajes para una mayor sostenibilidad ambiental; los impactos a los que está sometido el ambiente del AMR, en especial vinculado a sus ámbitos fluviales, demandan por parte de la sociedad nuevas acciones concretas y estrategias de actuación en el corto y mediano plazo, a fin de poder asegurar la preservación ambiental del AMR y de su valiosa matriz hídrica para las generaciones futuras.

\section{REFERENCIAS BIBLIOGRÁFICAS}

ALCALDÍA DE BARRANQUILLA. Plan de desarrollo: Soy Barranquilla 2020-2023. Barranquilla: Alcaldía de Barranquilla, 2020.

ANSALDI, María Delia; COREA, Mario y PLA, Lidia. Prefectura del Gran Rosario - Cuaderno No14 de Prefectura del Gran Rosario. Rosario: Sección de prensa y difusión Depto. Promoción y Desarrollo, 1972.

BARRANDEGUY, Tomás. Con el 2020 se van más de 300 mil hectáreas incendiadas en el Delta del río Paraná. Diario La Capital, 20 de diciembre de 2020. Recuperado de https://www.lacapital.com.ar/laciudad/con-el-2020-se-van-mas-300-mil-hectareas-incendiadas-el-delta-del-rio-parana-n2631286.html

BREEN, Anne \& RIGBY, Dick. Waterfronts cities reclaim their edge. New York-Londres: McGraw-Hill, 1994. 
BRUNDTLAND, Gro. Nuestro Futuro Común. Asamblea General de la Naciones Unidas, 1987. Recuperado de: http://www.ecominga.uqam.ca/PDF/BIBLIOGRAPHIE/GUIDE_LECTURE_1/CMMAD-InformeComision-Brundtland-sobre-Medio-Ambiente-Desarrollo.pdf

BUNCE, Susannah \& DESFOR, Gene. Introduction to "Political ecologies of urban waterfronts transformations". Cities, Vol. 24 (4), pp. 251-258, 2007. doi:10.1016/j.cities.2007.02.001

BUNCE, Susannah. Developing sustainability: sustainability policy and gentrification on Toronto's waterfront. Local Environment, Vol. 14 (7), pp. 651-667, 2009. doi:2067/10.1080/13549830903097740

CIUDAD DE BUENOS AIRES. Reporte local voluntario: Localización de la Agenda 2030 en la Ciudad de Buenos Aires. Buenos Aires, 2020.

CONSEJO DEL PLAN URBANO AMBIENTAL. Estudio sobre el futuro urbano: Actualización del Plan Urbano Ambiental. Buenos Aires, 2020.

MUNICIPALIDAD DE ROSARIO. Decreto Municipal N³4.983. Rosario: Municipalidad de Rosario, 1967.

DELLA PAOLERA, Carlos María; GUIDO, Angel y FARENGO, Alberto. Plan Regulador y de Extensión. Rosario: Municipalidad de Rosario, 1935.

ECOMR. Plan Urbano Local: Capitán Bermúdez 2030. Rosario: ECOM, 2018.

ECOMR. Plan Urbano Local: Acebal 2030. Rosario: ECOM, 2019a.

ECOMR. Plan Urbano Local: Villa Constitución 2030. Rosario: ECOM, 2019b.

FEIN, Mónica. Directrices de Ordenamiento Territorial. Bases para un Acuerdo Metropolitano. Cuaderno 3. Rosario: ECOM, 2014.

FRANCISCO. Carta Encíclica: Laudato Si. Sobre el cuidado de la casa común. Vaticano, 2015. Recuperado de: $\quad$ http://www.vatican.va/content/dam/francesco/pdf/encyclicals/documents/papafrancesco_20150524_enciclica-laudato-si_sp.pdf

GALIMBERTI, Cecilia. Planificar el territorio fluvial sudamericano: indagaciones sobre el paisaje deltaico del Gran Rosario. ZARCH 15, 2020. DOI: 10.26754/ojs_zarch/zarch.2020154614

GALIMBERTI, Cecilia. Las ciudades y el agua. Nuevas relaciones entre cultura-naturaleza en los frentes costeros contemporáneos. [i2] Investigación e Innovación en Arquitectura y Territorio, Vol. 9 (1), pp.3358, 2021. DOI: 10.14198/i2.2021.9.1.03

GORDON, David. Planning, design and managing change in urban waterfront redevelopment. The Town Planning Review, Vol. 67 (3), pp. 261-290, 1996. https://www.jstor.org/stable/40113388

LYTLE, Mark. The gentle subversive: Rachel Carson, Silent Spring and the rise of the environment movement. New York: Oxford University Press, 2007.

MATTHEWS, Geoffrey Vernon Townsend. The Ramsar Convention on Wetlands: Its History and Development. Gland. Ramsar Convention Bureau, 2013. Recuperado de: https://leap.unep.org/sites/default/files/2020-09/Matthews-history.pdf 
MCCARTHY, John. Waterfront regeneration in the Netherlands: The cases of Rotterdam and Maastricht. European Planning Studies, Vol. 4 (5), pp. 545-560, 1996. Doi: 10.1080/09654319608720365

MCHARG, Ian. Proyectar con la naturaleza. Barcelona: Gustavo Gili, 2000.

MCNAMARA, Robert. Discurso ante la conferencia de las Naciones Unidas sobre el Medio Humano. Washington: Banco Internacional de reconstrucción y Fomento, 1972. Recuperado de: https://openknowledge.worldbank.org/bitstream/handle/10986/33160/55786SP.pdf?sequence=5\&isAll owed $=\mathrm{y}$

MEYER, Hans. City and port. Transformations of Port Cities London, Barcelona, New York, Rotterdam. Utrecht: International Books, 1999.

MIKIELIEVICH, Wladimir. La posta de San Lorenzo. Un trillado error histórico. Revista Historia de Rosario, Vol. 25, pp. 21-48, 1973.

MINISTERIO DE AMBIENTE Y DESARROLLO SOSTENIBLE. Informe de superficies afectadas por incendios en el Delta e Islas del Río Paraná. Buenos Aires: Dirección Nacional de Planificación y Ordenamiento Ambiental del Territorio, 2020.

MOMTAZ, Djamchid. The United Nations and the protection of the environment: from Stockholm to Rio de Janeiro. Political Geography, Vol. 15 (3/4), pp. 261-271, 1996. doi:0962-6298(95)00109-3

MONTES, Alberto. Plan Rosario. Ley Nacional N ${ }^{\circ} 16.052$ y sus antecedentes. Rosario: Centro de Estudios Nacionales, Provinciales y Municipales, 1964.

MONGFELD, Oscar. El Área Metropolitana de Rosario y el Pago de los Arroyos. Rosario: Centro de Estudios Urbanos de Rosario, 1983.

MUMFORD, Lewis. Introducción de Lewis Mumford a la primera edición. En: Ian McHarg, Proyectar con la Naturaleza. Barcelona: Editorial Gustavo Gili. pp. XVI - XVII, 2000.

MUMFORD, Lewis. La ciudad en la historia: Sus orígenes, transformaciones y perspectivas. Logroño: Pepitas de calabaza, 2014.

MUNICIPALIDAD DE ROSARIO. Actualización del Plan Regulador y Bases Documentales para la revisión del Código Urbano. Rosario: Municipalidad de Rosario, 1991.

MUNICIPALIDAD DE ROSARIO. Plan Estratégico Rosario. Rosario: MR, 1998.

MUNICIPALIDAD DE ROSARIO (1999). Plan Director de Rosario. Bases para el acuerdo. Rosario: MR, 1999.

MUNICIPALIDAD DE ROSARIO. Plan Urbano Rosario 2007-2017. Rosario: MR, 2011.

MUNICIPALIDAD DE ROSARIO. Plan Ambiental de Rosario. Rosario: MR, 2016.

MUNICIPALIDAD DE ROSARIO. Plan Estratégico Rosario 2030. Rosario: MR, 2018.

MUNICIPALIDAD DE ROSARIO. Bases para la actualización del Plan Urbano Rosario [5+5]. Rosario: MR, 2019.

NACIONES UNIDAS. Nueva Agenda Urbana. Quito: Habitat III, 2017. 
NDUBIDISI, Forster. Ecological Planning: A Historical and Comparative Synthesis. Baltimore: The Johns Hopkins University Press, 2002.

ROME, Adam. "Give Earth a Chance": The Environmental Movement and the Sixties. Journal of American History, Vol. 90 (2), pp. 525-554, 2003. https://doi.org/10.2307/3659443

SECRETARÍA DE AMBIENTE Y DESARROLLO SUSTENTABLE. Plan Integral Estratégico para la Conservación y Aprovechamiento Sostenible en el Delta del Paraná, 2008. Disponible en: https://www.mininterior.gov.ar/planificacion/pdf/planes-reg/Plan-Integral-Estrategico-para-laConservacion-y-Aprovechamineto-Sostenible-en-el-Delta-del-Parana-(Entre\%20Rios,-Santa\%20Fe,Buenos\%20Aires).pdf

SECRETARÍA DE AMBIENTE Y DESARROLLO SUSTENTABLE. Plan Integral Estratégico para la Conservación y el Aprovechamiento Sostenible de la Región Delta del Paraná, 2014. Disponible en: https://www.entrerios.gov.ar/deltasustentable/userfiles/files/1-Documento\%20PIECAS\%20DP.pdf

STEINER, Frederick (Ed.). The essential lan McHarg: writings on design and nature. Washington: Island Press, 2006.

YANG, Bo \& LI, Shujuan. Design with Nature: Ian McHarg's ecological wisdom as actionable and practical knowledge. Landscape \& Urban Planning, Vol. 155, pp. 21-32, 2016. https://doi.org/10.1016/j.landurbplan.2016.04.010

YARO, Robert. Foreward. En: Ian McHarg \& Frederick Steiner, To heal the earth: Selected writings of Ian L. McHarg. Washington: Island Press, 1998.

Trabalho enviado em 26 de junho de 2021 Aceito em 18 de agosto de 2021 